4. Selective cooling of the spinal cord eliminates complications related to general hypothermia.

Although it is too soon to draw any conclusions regarding the effectiveness of this method of spinal protection, I believe that further clinical studies should be done. The results of the animal experiments have been encouraging., 2

Addendum. Since this manuscript was accepted for publication, this method of spinal protection has been used in two more patients requiring resection of arteriosclerotic thoracoabdominal aneurysm. The first patient was a 74-year-old man with a contained rupture of a thoracoabdominal aneurysm originating at the takeoff of the left subclavian artery down to the infrarenal aorta, where a graft had previously been placed for an abdominal aortic aneurysm. The crossclamp time was 46 minutes. The second patient was a 71-year-old man, also with a history of previously resected abdominal aortic aneurysm, who presented with a large asymptomatic thoracoabdominal aneurysm. The aneurysm involved the entire descending thoracic aorta and terminated right below the diaphragm. The aorta was crossclamped for 50 minutes. Both patients did well without any neurologic complications.

\section{REFERENCES}

1. Berguer R, Porto J, Fedoronko B, et al. Selective deep hypothermia of the spinal cord prevents paraplegia after aortic cross-clamping in the dog model. $\mathrm{J}$ Vasc Surg 1992;15:62-72.

2. Salzano R, Ellison L, Altonji $\mathbf{P}$, et al. Regional deep hypothermia of the spinal cord protects against ischemic injury during thoracic aortic cross-clamping. Ann Thorac Surg 1994;57:65-71.
3. Breckwoldt WL, Genco CM, Connolly RJ, et al. Spinal cord protection during aortic occlusion: efficacy of intrathecal tetracaine. Ann Thorac Surg 1991;51:95963.

4. Colon R, Frazier OH, Cooley DA, et al. Hypothermic regional perfusion for protection of the spinal cord during periods of ischemia. Ann Thorac Surg 1987;43: 639-43.

5. Crawford ES, Svensson LG, Hess KR, et al. A prospective randomized study of cerebrospinal fluid drainage to prevent paraplegia after high-risk surgery on the thoracoabdominal aorta. J Vasc Surg 1990;13:36-46.

6. Crawford ES, Mizrahi EM, Hess KR, et al. The impact of distal aortic perfusion and somatosensory evoked potential monitoring on prevention of paraplegia after aortic aneurysm operation. J THORAC CARDIOvasC SuRg 1988;95:357-67.

7. Crawford ES, Coselli JS, Safi HJ. Partial cardiopulmonary bypass, hypothermic circulatory arrest, and posterolateral exposure for thoracic aortic aneurysm operation. J Thorac CARdiovasc SuRg 1987;94:824-7.

8. Elmore JR, Gloviczki P, Harper CH Jr, et al. Spinal cord injury in experimental thoracic aortic occlusion: investigation of combined methods of protection. $\mathrm{J}$ Vasc Surg 1992;15:789-99.

9. Kouchoukos NT, Wareing TH, Izumoto $\mathrm{H}$, et al. Elective hypothermic cardiopulmonary bypass and circulatory arrest for spinal protection during operations on the thoracoabdominal aorta. J THORAC CARDIOvaSC SuRG 1990;99:659-64.

\title{
SUCCESSFUL OPERATION FOR SOLITARY FIBROUS TUMOR OF THE EPICARDIUM
}

\author{
Daisuke Segawa, MD, ${ }^{a}$ Hiroshi Yoshizu, MD, ${ }^{\mathrm{a}}$ Yoshiyuki Haga, MD, ${ }^{\mathrm{a}}$ Nobuo Hatori, MD, ${ }^{\text {a }}$ Susumu Tanaka, MD, \\ and Shinsuke Aida, MD, ${ }^{\mathrm{b}}$ Saitama, Japan
}

Solitary fibrous tumors, which mostly arise from the pleura, are not common, and lesions growing from the epicardium are extremely rare. We present a case of an epicardial solitary fibrous tumor that was found as an enlarged mediastinal shadow in a chest roentgenogram and was resected after $2 \frac{1 / 2}{2}$ years' observation.

From the Department of Surgery II $^{\mathrm{a}}$ and the Department of Laboratory Medicine, ${ }^{\mathrm{b}}$ The National Defense Medical College, Saitama, Japan.

J THORAC CARDIOVASC SuRg 1995;109:1246-8

Copyright (C) 1995 by Mosby-Year Book, Inc.

$0022-5223 / 95 \$ 3.00+0 \quad \mathbf{1 2 / 8 / 5 8 6 1 1}$
A 50-year-old woman was referred to the National Defense Medical College Hospital in November 1990 with a suspected ventricular aneurysm. Ultrasonic echocardiography revealed that it was a solid mass attached to the right ventricle with a stalk. Surgical resection was recommended to the patient, but she refused because of no subjective symptoms. She was thus followed up in the outpatient clinic.

About $2 \frac{1}{2}$ years later, the patient was admitted to our hospital because of dyspnea and palpitation in the right lateral decubitus position. A chest roentgenogram demonstrated enlargement of the mass after the $2 \frac{1}{2}$ years of follow-up (Fig. 1). The computed tomographic scan and the magnetic resonance image revealed that the lesion 

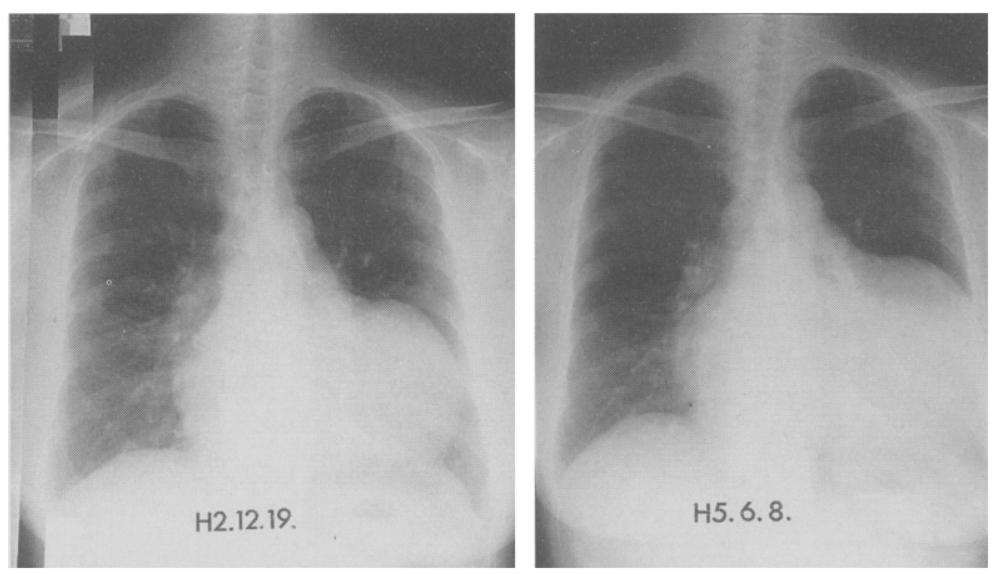

Fig. 1. Chest x-ray films. Left, In December 1990, the film showed marked cardiomegaly. Right, In June 1993, the film showed enlargement of this shadow.

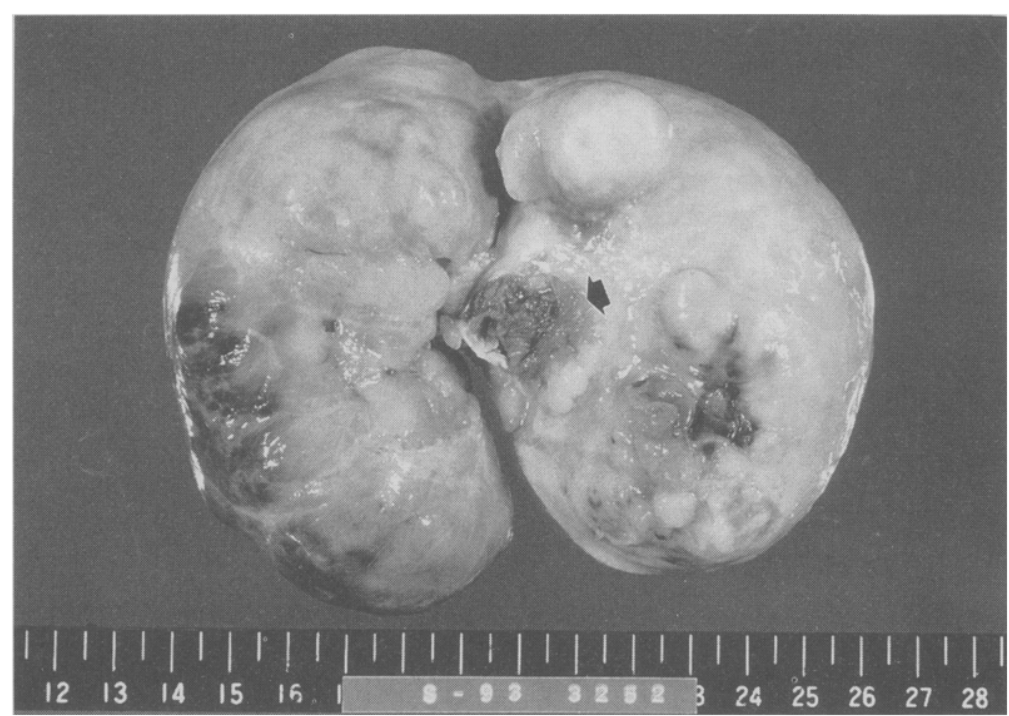

Fig. 2. Gross appearance of the tumor with a narrow-based pedicle and the right ventricular muscle (arrow).

grew in the pericardial cavity and was contiguous with the right ventricular wall.

The mass was surgically resected on June 15,1993 . On entering the pericardial cavity through a median sternotomy, we encountered a pear-shaped whitish mass the size of a child's head. The lesion grew from the right ventricular wall on a narrow-based pedicle and did not adhere to the pericardium. Partial resection of the right ventricular muscle was inevitable for total surgical resection. With the aid of cardiopulmonary bypass, the lesion was resected together with the right ventricular muscle contiguous with the pedicle. Because the defect in the right ventricular wall was close to the left anterior descending coronary artery, the defect was sandwiched with two strips of
Dacron felt with suture running beneath the coronary vessels to avoid arterial occlusion.

The lesion was an encapsulated tumor $12.5 \times$ $10.5 \times 8.0 \mathrm{~cm}$ in size and $530 \mathrm{gm}$ in weight (Fig. 2). Histologically, the tumor consisted of spindle-shaped and multiangle tumor cells with admixture of different cell types. In the hypercellular areas, the tumor cells and intercellular collagen fibers proliferated without obvious structure, which corresponded to the so-called "patternless" arrangement described as a feature of solitary fibrous tumor ${ }^{3}$ (Fig. 3). High vascularity with a hemangiopericytoma-like pattern was also observed. Irregularity of the nuclear shape was conspicuous and mitotic figures were relatively frequent ( 2 to 5 per 10 high-power fields). 


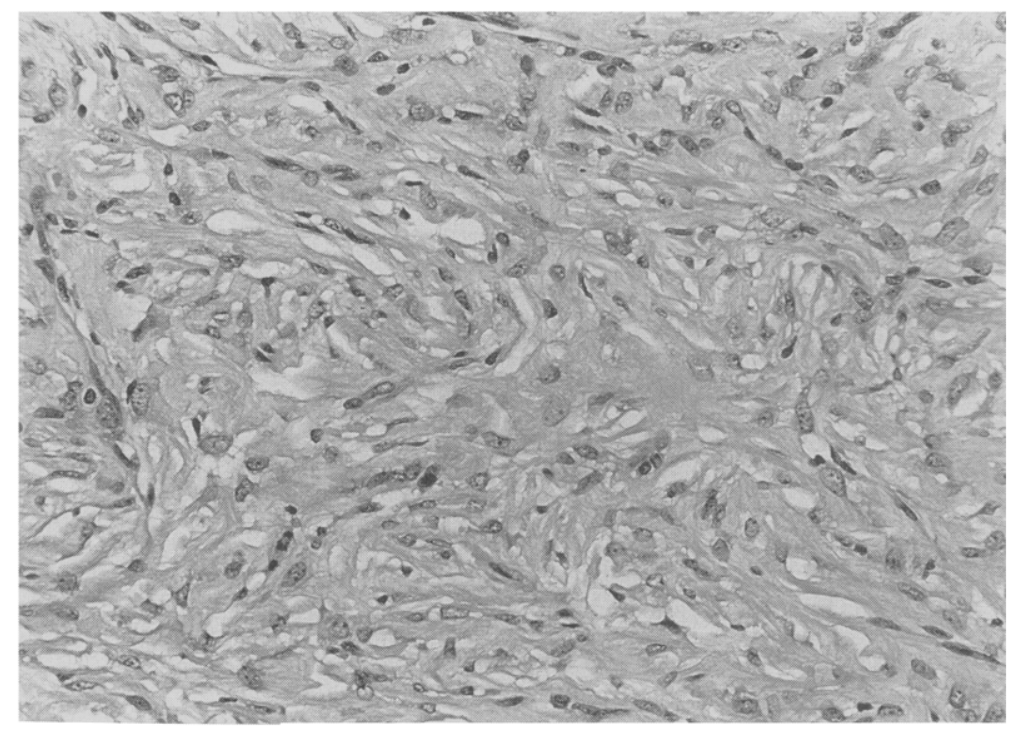

Fig. 3. Photomicrograph of the hypercellular area of the tumor showing "patternless" arrangement of tumor cells and intercellular collagen fibers. Irregularity of the nuclear shape is also observed. (Hematoxylin-eosin stain; original magnification $\times 200$.)

In the hypocellular areas, hyalinization and mucinous degeneration of intercellular collagen was prominent. Immunohistochemically, the tumor cells were positive for vimentin and negative for cytokeratin, actin, and s-100 protein. These gross and microscopic findings were compatible with those of solitary fibrous tumor.

The postoperative course was entirely uneventful, and the patient was discharged from the hospital on the fourteenth postoperative day. She has been free from recurrence for 19 months.

Solitary fibrous tumor, which has also been known as localized fibrous mesothelioma, was first classified as a pleural neoplasm by Klemperer and Rabin ${ }^{1}$ in 1931. Although solitary fibrous tumors most commonly arise from the pleura, several have recently been reported to arise in extrapleural sites such as the upper respiratory tract and other serosal cavities., ${ }^{2,3}$ Among them, lesions that arise from the epicardium are so rare that we could find no reported case in reviewing the literature. Three such lesions arising from the pericardium and growing in the pericardial cavity have been reported so far. ${ }^{3-5}$

Most solitary fibrous tumors are cured by surgical excision but some may be lethal because of extensive intrathoracic growth, unresectable recurrences, and metastatic diffusion. ${ }^{2-5}$ We consider that surgical resection is the best treatment for solitary fibrous tumors if they are resectable. Tumors must be resected with a margin free of tumor cells. Epicardial solitary fibrous tumors may arise in the vicinity of the coronary artery, as in our case. In such cases it is important to repair the defect on the ventricular wall to avoid damage to the coronary artery.

\section{REFERENCES}

1. Klemperer $P$, Rabin CB. Primary neoplasms of the pleura: a report of five cases. Arch Pathol 1931;11:385412.

2. Goodlad JR, Fletcher CDM. Solitary fibrous tumor arising at unusual sites: analysis of a series. Histopathology 1991;19:515-22.

3. El-Naggar AK, Ro JY, Ayala AG, Ward R, Ordones NG. Localized fibrous tumor of the serosal cavities: immunohistochemical, electron-microscopic, and flow cytometric DNA study. Am J Clin Pathol 1989;92: 561-5.

4. Bortolotti U, Calabro F, Loy M, Fasoli G, Altavilla G, Marchese D. Giant intrapericardial solitary fibrous tumor. Ann Thorac Surg 1992;54:1216-8.

5. Roggli VL, Kolbeck J, Sanfilippo F, Shelburne JD. Pathology of human mesothelioma: etiologic and diagnostic considerations. In: Rosen PP, Fecher RE, eds. Pathology annual. Part 2, Vol 22. Norwalk: Appleton \& Lange, 1987:91-131. 